\title{
Borrelia miyamotoi and Borrelia burgdorferi (sensu lato) identification and survey of tick-borne encephalitis virus in ticks from north-eastern Germany
}

\author{
Cristian Răileanu', Oliver Tauchmann ${ }^{1}$, Ana Vasić ${ }^{1}$, Elisabeth Wöhnke ${ }^{1,2}$ and Cornelia Silaghi ${ }^{1,2,3^{*}}$
}

\begin{abstract}
Background: Ixodes ricinus is the most common tick species in Europe and the main vector for Borrelia burgdorferi (sensu lato) and tick-borne encephalitis virus (TBEV). It is involved also in the transmission of Borrelia miyamotoi, a relapsing fever spirochete that causes health disorders in humans. Little is known regarding the circulation of Borrelia species and the natural foci of TBEV in north-eastern Germany. The goal of this study was to investigate the infection rates of Borrelia spp. and of TBEV in I. ricinus ticks from north-eastern Germany.
\end{abstract}

Methods: Ticks were collected by flagging from 14 forest sites in Mecklenburg-Western Pomerania between April and October 2018. RNA and DNA extraction was performed from individual adult ticks and from pools of 2-10 nymphs. Real time reverse transcription PCR (RT-qPCR) targeted the $3^{\prime}$ non-coding region of TBEV, while DNA of Borrelia spp. was tested by nested PCR for the amplification of 16S-23S intergenic spacer. Multilocus sequence typing (MLST) was performed on B. miyamotoi isolates.

Results: In total, 2407 ticks were collected (239 females, 232 males and 1936 nymphs). Female and male I. ricinus ticks had identical infection rates (both 12.1\%) for Borrelia spp., while nymphal pools showed a minimum infection rate (MIR) of 3.3\%. Sequencing revealed four Borrelia species: B. afzelii, B. garinii, B. valaisiana and B. miyamotoi. Borrelia afzelii had the highest prevalence in adult ticks (5.5\%) and nymphs (MIR of 1.8\%). Borrelia miyamotoi was identified in 3.0\% of adults and registered the MIR of $0.8 \%$ in nymphs. Borrelia valaisiana was confirmed in $2.5 \%$ adult ticks and nymphs had the MIR of $0.7 \%$, while B. garinii was present in $1.1 \%$ of adults and showed a MIR of $0.1 \%$ in nymphs. The MLST of B. miyamotoi isolates showed that they belong to sequence type 635. No tick sample was positive after RT-qPCR for TBEV RNA.

Conclusions: The prevalence of B. miyamotoi in I. ricinus ticks registered similar levels to other reports from Europe suggesting that this agent might be well established in the local tick population. The detection of B. burgdorferi (s.l.) indicates a constant circulation in tick populations from this region.

Keywords: Ixodes ricinus, Lyme borreliosis, Borrelia miyamotoi, Tick-borne encephalitis virus, Mecklenburg-Western Pomerania

*Correspondence: cornelia.silaghi@fli.de

${ }^{2}$ Institute of Molecular Virology and Cell Biology, Friedrich-LoefflerInstitut, Greifswald-Insel Riems, Germany

Full list of author information is available at the end of the article

\section{Background}

Ixodid ticks transmit the greatest variety of human and animal pathogens compared to any other arthropod [1]. Ixodes ricinus is the most widespread hard tick species in Europe and Germany $[2,3]$ known to feed on many

c) The Author(s) 2020. This article is licensed under a Creative Commons Attribution 4.0 International License, which permits use, sharing, adaptation, distribution and reproduction in any medium or format, as long as you give appropriate credit to the original author(s) and the source, provide a link to the Creative Commons licence, and indicate if changes were made. The images or other third party material in this article are included in the article's Creative Commons licence, unless indicated otherwise in a credit line to the material. If material is not included in the article's Creative Commons licence and your intended use is not permitted by statutory regulation or exceeds the permitted use, you will need to obtain permission directly from the copyright holder. To view a copy of this licence, visit http://creativeco mmons.org/licenses/by/4.0/. The Creative Commons Public Domain Dedication waiver (http://creativecommons.org/publicdomain/ zero/1.0/) applies to the data made available in this article, unless otherwise stated in a credit line to the data. 
different vertebrate hosts. The most relevant pathogens for which $I$. ricinus is a competent vector are Borrelia burgdorferi (sensu lato), the agent responsible for Lyme disease and the tick-borne encephalitis virus (TBEV) [4, 5]. Spirochetes of the B. burgdorferi (s.l.) complex can cause Lyme borreliosis, the most frequent tick-borne disease of humans in the Northern Hemisphere [6].

In Europe, each year tens of thousands of human cases are being reported [7]. In Germany, Lyme borreliosis is the most common tick-borne disease in humans, registering between 2013 and 2017 mean annual incidence rates on district level from $0.5 / 100,000$ up to $138 / 100,000$ [8]. Currently, 22 genospecies belonging to the B. burgdorferi (s.l.) complex exist, out of which 11 are circulating in Europe [9]. In humans, Lyme borreliosis is a multi-systemic disease that evolves under several clinical manifestations: erythema migrans (most frequent); Lyme arthritis; Lyme carditis; and neuroborreliosis [10]. Detection of B. burgdorferi (s.l.) in ticks from Germany was reported in several studies, prevalence rates ranging from $2 \%$ up to $36.2 \%$ in the southern part of the country [11-19].

Borrelia miyamotoi is the only member of the relapsing fever group for which I. ricinus represents the main vector in Europe [20], causing influenza-like symptoms in humans characterized by fever, nausea, myalgia, fatigue, headache or chills [21].

Interestingly, information regarding the presence of $B$. miyamotoi in ticks from Northern Germany was lacking until 2018 when the first prevalence for this pathogen was published, $2.1 \%$ of $I$. ricinus ticks (8.9\% of Borrelia spp. positive specimens) collected from the city of Hannover being positive by reverse line blot [16]. Positive I. ricinus ticks for B. miyamotoi were also detected in Western and Southern Germany, with infection rates varying from $1.8 \%$ to $2.7 \%[11,17]$.

Tick-borne encephalitis virus (TBEV) is the main viral agent transmitted by I. ricinus ticks in Europe [22]. It belongs to genus Flavivirus, family Flaviviridae and has three main subtypes: TBE-Eu (European sub-type) circulating in Europe; TBE-FE (Far East) found in Asia; and TBE-Sib (Siberia) located in Russia and reaching also eastern part of Europe [22]. The virus has an endemic occurrence in 27 countries in Europe [23], with the Czech Republic, the Baltic countries, and Slovenia registering the highest annual incidence rates $(5-18.6 / 100,000)$ [24]. It can cause severe central nervous system infections in humans that can be fatal [25]. Infections with TBEV are mostly located in Southern Germany, 89\% of human cases occurring in Bavaria and Baden-Wurttemberg [26].

Mecklenburg-Western Pomerania is considered a low risk area for TBE but isolated cases of infection were reported between 2002 and 2018 [26]. In 2004, the first autochthonous human case was registered after 19 years [27]. Furthermore, detection of TBEV in questing I. ricinus was found in 2007 for the first time since 1992 [28]. Later studies found anti-TBEV-IgG antibodies in wild game [29], sheep and goats [30].

The goal of the present study was to investigate the occurrence of Borrelia spp. and tick-borne encephalitis virus in I. ricinus ticks in Mecklenburg-Western Pomerania. Furthermore, multilocus sequence typing (MLST) for B. miyamotoi was performed, a pathogen for which there is still a lack of data regarding its circulation in ticks from Northern Germany.

\section{Methods}

\section{Study sites and ticks}

Study sites were 14 forested habitats in the north-eastern part of Mecklenburg-Western Pomerania (12 sites from mainland of Mecklenburg-Western Pomerania and 2 sites from the island of Ruegen; Fig. 1). The tick collection took place from April to October 2018, by flagging a $1 \mathrm{~m}^{2}$ white cotton material on the low vegetation and regularly checking it for ticks. The collection was performed monthly in three locations (1, Kieshof; 3 , Weitenhagen; and 7, Mannhagen), while for the rest of the sites, ticks were obtained after only one visit (Table 1).

\section{Processing tick samples}

After collection, ticks were transferred alive to the laboratory. We performed two washing steps of ticks; first washing in $70 \%$ ethanol for $5 \mathrm{~min}$, followed by a second wash in a distilled water bath for 5 min. Ticks

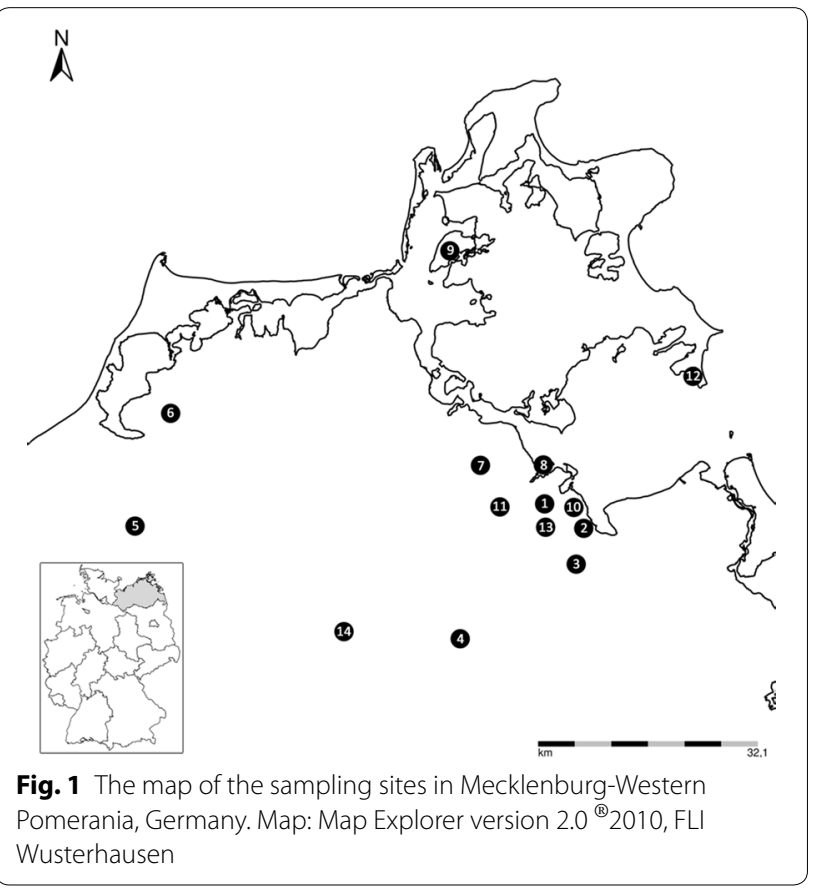


Table 1 Number of collected ticks from each study site in Mecklenburg-Western Pomerania

\begin{tabular}{|c|c|c|c|c|c|c|}
\hline \multirow[t]{2}{*}{ Site } & \multirow[t]{2}{*}{ Location } & \multicolumn{4}{|c|}{ Collected Ixodes ricinus ticks } & \multirow[t]{2}{*}{ Coordinates } \\
\hline & & $\mathrm{F}$ & M & N & Total & \\
\hline 1 & Kieshof ${ }^{a}$ & 123 & 149 & 1134 & 1406 & $54.130256 \mathrm{~N}, 13.345506 \mathrm{E}$ \\
\hline 2 & Ryck & 3 & 2 & 10 & 15 & $54.095043 \mathrm{~N}, 13.429127 \mathrm{E}$ \\
\hline 3 & Weitenhagen $^{\mathrm{a}}$ & 79 & 43 & 501 & 623 & $54.048814 \mathrm{~N}, 13.407368 \mathrm{E}$ \\
\hline 4 & Loitz & - & 1 & 4 & 5 & $53.96054 \mathrm{~N}, 13.13994 \mathrm{E}$ \\
\hline 5 & Carlsruhe & - & - & 7 & 7 & $54.13068 \mathrm{~N}, 12.43077 \mathrm{E}$ \\
\hline 6 & Tempel & - & 3 & 33 & 36 & $53.96054 \mathrm{~N}, 13.13994 \mathrm{E}$ \\
\hline 7 & Mannhagen ${ }^{a}$ & 14 & 7 & 128 & 149 & $54.185725 \mathrm{~N}, 13.207810 \mathrm{E}$ \\
\hline 8 & Riems & 9 & 17 & 4 & 30 & $54.181194 \mathrm{~N}, 13.347872 \mathrm{E}$ \\
\hline 9 & Ummanz & 1 & - & 36 & 37 & $54.468392 \mathrm{~N}, 13.167908 \mathrm{E}$ \\
\hline 10 & Ladebow & - & 1 & 12 & 13 & $54.113863 \mathrm{~N}, 13.416879 \mathrm{E}$ \\
\hline 11 & Horst & 8 & 6 & 8 & 22 & $54.129832 \mathrm{~N}, 13.245665 \mathrm{E}$ \\
\hline 12 & Thiesow & 1 & 3 & 54 & 58 & $54.284438 \mathrm{~N}, 13.694322 \mathrm{E}$ \\
\hline 13 & Wackerow & 1 & - & - & 1 & $53.96054 \mathrm{~N}, 13.13994 \mathrm{E}$ \\
\hline 14 & Annenhof & - & - & 5 & 5 & $53.96054 \mathrm{~N}, 13.13994 \mathrm{E}$ \\
\hline Total & & 239 & 232 & 1936 & 2407 & \\
\hline
\end{tabular}

a Monthly collection of ticks from April to October 2018

Abbreviations: $\mathrm{F}$, females; $\mathrm{M}$, males; $\mathrm{N}$, nymphs; -, no collected ticks

were dried with paper tissues and then were subjected to morphological identification using taxonomical identification keys [31]. After identification, ticks were stored at $-80{ }^{\circ} \mathrm{C}$ until further analysis. Homogenization of ticks was performed from each individual adult tick and from pools of nymphs (2 to 10 nymphs in each pool). Nymphs were pooled based on the collection site. Tick lysis was performed in a $2 \mathrm{ml}$ tube, using one $5 \mathrm{~mm}$ metal bead and $300 \mu \mathrm{l}$ modified minimum essential medium (Collection of Cell Lines in Veterinary Medicine, Friedrich-Loeffler-Institut, Germany) supplemented with $10 \%$ fetal calf serum. Homogenization was achieved using a TissueLyser II (Qiagen, Venlo, Netherlands) at $30 \mathrm{~Hz}$, repeated twice for $1 \mathrm{~min}$. Following tick lysis, each tube was centrifuged at $1500 \times$ rpm for 2 min. DNA and RNA extraction was performed from $100 \mu \mathrm{l}$ aliquots with GeneJET Genomic DNA Purification kit and GeneJET RNA Purification Kit, respectively, according to the manufacturer instructions (Thermo Fisher Scientific, Waltham, USA). Purified RNA and DNA were eluted in $100 \mu \mathrm{l}$ RNAse free water and elution buffer, respectively.

\section{Detection of Borrelia spp. by nested PCR, sequencing and phylogenetic analysis}

Detection of Borrelia species in ticks was performed by a nested PCR using specific outer and inner primers for the 16S-23S intergenic spacer (16S-23S IGS) (Table 2) [32]. The amplification of a fragment of approximatively $1007 \mathrm{bp}$ (size varies with the Borrelia species) in the first PCR and a fragment of 388-685 bp in the second PCR was performed as previously described [32], using GoTaq ${ }^{\circledR}$ Flexi DNA Polymerase kit (Promega, Madison, USA). The PCR products from the nested PCR were separated on a 1.5\% agarose gel stained with Roti $^{\circledR}$-GelStain Red (Carl Roth GmbH, Karlsruhe, Germany) and visualised with ChemiDoc ${ }^{\mathrm{TM} M}$ MP Imaging system (Bio-Rad Laboratories, Hercules, USA).

Positive samples were further processed for sequencing, first being purified with NucleoSEQ ${ }^{\circledR}$ kit (Mackerey Nigel, Düren, Germany) following the manufacturer instructions, and then sequenced on the ABI PRISM ${ }^{\circledR}$ 3130 sequencer in both directions using the inner primers (Table 2) [32], at the Institute of Diagnostic Virology, Friedrich-Loeffler-Institut, Germany.

The obtained nucleotide sequences were viewed and edited in Geneious 11.1.5 (https://www.geneious.com) and compared with data available in the GenBank database using BLASTn. Consensus Borrelia 16S-23S IGS sequences were deposited in the GenBank database under the Accession numbers MK945767-MK945887.

For performing the phylogenetic analysis, we have selected 20 representative Borrelia sequences and reference sequences from GenBank that had high rates of similarity, totalizing 39 nucleotide sequences. The tree was constructed by using the Maximum Likelihood method based on the Tamura 3-parameter model [33]. Borrelia turicatae (GenBank: MH620367) and B. hermsii (GenBank: KC883470) were used as the outgroup. The phylogenetic analysis was conducted in MEGA7 [34]. 


\section{Multilocus sequence typing of Borrelia miyamotoi}

Multilocus sequence typing (MLST) was performed for seven samples that tested positive in nested PCR for 16S23S IGS B. miyamotoi (GenBank: MK945785; MK945806; MK945817; MK945824; MK945861; MK945865; and MK945867). The selected seven samples were included in a PCR reaction using specific primer sets for the amplification of nifS, clpA, rplB, pyrG, recG, clpX, pepX and $u v r A$ gene fragments for each sample, as previously described (Table 2) [35] with slight modifications. The amplification of targets was performed using GoTaq $^{\circledR}$ G2 Flexi DNA
Polymerase kit (Promega). For nifS and $\operatorname{clp} A$ gene fragments, a touchdown PCR was undertaken by an initial denaturation step at $95^{\circ} \mathrm{C}$ for $2 \mathrm{~min}$, followed by a first set of cycles with annealing conditions at $58{ }^{\circ} \mathrm{C}$ decreasing with $1{ }^{\circ} \mathrm{C}$ until $50^{\circ} \mathrm{C}$ for $30 \mathrm{~s}$ and extension at $72{ }^{\circ} \mathrm{C}$ for $60 \mathrm{~s}$. Each reaction included 40 additional cycles at $95{ }^{\circ} \mathrm{C}$ for $30 \mathrm{~s}$, $50{ }^{\circ} \mathrm{C}$ for $30 \mathrm{~s}$ and $72{ }^{\circ} \mathrm{C}$ for $60 \mathrm{~s}$, followed by a final extension step at $72{ }^{\circ} \mathrm{C}$ for $5 \mathrm{~min}$.

For the remaining six targets $(r p l B, p y r G, \operatorname{rec} G, c l p X$, pep $X$ and $u v r A$ ), the touchdown PCR included a denaturation at $95^{\circ} \mathrm{C}$ for $2 \mathrm{~min}$, followed by a first set of cycles

Table 2 Primer pairs used for detection or for the MLST of selected targets of Borrelia spp. in I. ricinus ticks

\begin{tabular}{|c|c|c|c|c|}
\hline Pathogen & Target & Primer/Probe & Sequence $\left(5^{\prime}-3^{\prime}\right)$ & References \\
\hline \multirow[t]{4}{*}{ Borrelia spp. } & \multirow[t]{4}{*}{$16 \mathrm{~S}-23 \mathrm{~S}$ rRNA } & Bospp-IGS-F & GTATGTTTAGTGAGGGGGGTG & \multirow[t]{4}{*}{ [32] } \\
\hline & & Bospp-IGS-R & GGATCATAGCTCAGGTGGTTAG & \\
\hline & & Bospp-IGS-Fi & AGGGGGGTGAAGTCGTAACAAG & \\
\hline & & Bospp-IGS-Ri & GTCTGATAAACCTGAGGTCGGA & \\
\hline \multirow[t]{28}{*}{ B. miyamotoi } & \multirow[t]{2}{*}{ nifs } & BmnifF31 & GAAAAAGTAAACTCCCTCAGAAAGG & \multirow[t]{2}{*}{ [35] } \\
\hline & & BmnifR892 & CAATGATGCCTGCAATATTTGGTG & \\
\hline & \multirow[t]{2}{*}{ clpA } & BmclpAF1268 & TTGATCTCTTAGATGATCTTGG & \multirow[t]{2}{*}{ [35] } \\
\hline & & BmclpAR2051 & CAAACATAAACCTTTTCAGCCTTTAATA & \\
\hline & \multirow[t]{2}{*}{$r l p B$} & BmrplF18 & ATTAAGACTTATARGCCAAAAAC & \multirow[t]{2}{*}{ [35] } \\
\hline & & BmrplR761 & GGCTGNCCCCAAGGWGAT & \\
\hline & \multirow[t]{2}{*}{ pyrG } & BmpyrF415 & CTTYTAGTWATTGARATTGGTGGT & \multirow[t]{2}{*}{ [35] } \\
\hline & & BmpyrR1261 & CAGCATCAAYTATRCCACAAAC & \\
\hline & \multirow[t]{2}{*}{ recG } & BmrecF908 & CTAGYATTCCTYTAATTGAGGC & \multirow[t]{2}{*}{ [35] } \\
\hline & & BmrecR1779 & TTCRGTTAAAGGTTCCTTATAAAG & \\
\hline & \multirow[t]{2}{*}{ clpX } & BmclpXF104 & CTGTTGCYATTTGTTTTGAATGC(Y)TC & \multirow[t]{2}{*}{ [35] } \\
\hline & & BmclpXR1277 & TAAAGTTCTTTTGCCCAAGG & \\
\hline & \multirow[t]{2}{*}{ pepX } & BmpepXF361 & AGAGAYTTAAGYTTAKCAGG & \multirow[t]{2}{*}{ [35] } \\
\hline & & BmpepXR1202 & GTTTCTCTTAAAGAYTGCATTCC & \\
\hline & \multirow[t]{2}{*}{ uvrA } & BmuvrF1435 & GCTKAAATTTTTRATTGATGTTGGA & \multirow[t]{2}{*}{ [35] } \\
\hline & & BmuvrR2306 & CARGGAACAAAAACATCRGGC & \\
\hline & \multirow[t]{2}{*}{$r p / B^{a}$} & BmrplF23 & GACTTATAGGCCAAAAACTTC & \multirow[t]{2}{*}{ [35] } \\
\hline & & Bmrpl759R & GATACAGGATGACGACCACC & \\
\hline & \multirow[t]{2}{*}{$\operatorname{pyr} G^{\mathrm{a}}$} & BmpyrF417 & TTTAGTAATTGAGATTGGTGGTAC & \multirow[t]{2}{*}{ [35] } \\
\hline & & Bmpyr1252R & TATTCCACAAACATTACGAGC & \\
\hline & \multirow[t]{2}{*}{$\operatorname{rec} G^{a}$} & BmrecF909 & TAGCATTCCTTTAGTTGAGGC & \multirow[t]{2}{*}[35]{} \\
\hline & & Bmrec1671R & CTCAGCATGCTCAACTACC & \\
\hline & \multirow[t]{2}{*}{$c \mid p X^{a}$} & BmclpF268 & TTATCTGTTGCTGTTTATAATC & \multirow[t]{2}{*}[35]{} \\
\hline & & BmclpX1155R & TTCAAACATAACATCTTTAAGTAATTCTTC & \\
\hline & \multirow[t]{2}{*}{ pep $X^{a}$} & BmpepF361 & AGAGACTTAAATTTAGCAGGAGTTG & {$[35]$} \\
\hline & & Bmpep1187R & TGCATTCCCCACATTGGAGTTC & \\
\hline & $u v r A^{a}$ & BmuvrF1437 & TTAAATTTTTAATTGATGTTGGACT & [35] \\
\hline & & Bmuvr2147R & TCTGTAAAAAACCCAACATAAGTTGC & \\
\hline TBEV & $3^{\prime}$ non-coding region & F_TBE_1 & GGGCGGTTCTTGTTCTCC & {$[36]$} \\
\hline & & R_TBE_1 & ACACATCACCTCCTTGTCAGACT & \\
\hline & & TBE-probe-WT & TGAGCCACCATCACCCAGACACA & \\
\hline
\end{tabular}

\footnotetext{
${ }^{a}$ Sequencing primers used in the second round of amplification and for sequencing the PCR products
} 
with an annealing temperature at $60{ }^{\circ} \mathrm{C}$ decreasing with $1{ }^{\circ} \mathrm{C}$ each cycle until $52^{\circ} \mathrm{C}$ and an extension step at $72{ }^{\circ} \mathrm{C}$ for $60 \mathrm{~s}$. Additionally, 40 cycles were run at $95^{\circ} \mathrm{C}$ for $30 \mathrm{~s}$, annealing at $50{ }^{\circ} \mathrm{C}$, extension at $72{ }^{\circ} \mathrm{C}$ for $60 \mathrm{~s}$ and a final extension step at $72{ }^{\circ} \mathrm{C}$ for $5 \mathrm{~min}$. PCR products from the reactions targeting $r p l B$, pyrG, $\operatorname{rec} G, c l p X$, pep $X$ and $u v r A$ were included in a nested PCR reaction, using sequencing primers (inner primers) for another round of amplification for 35 cycles, annealing temperature being set at $50^{\circ} \mathrm{C}$ (Table 2) [35]. Sequences obtained for MLST analysis were aligned and compared to the available sequences from the MLST database by using the sequence query option (http://pubmlst.org/borrelia).

\section{Analysis of ticks for the detection of tick-borne encephalitis virus}

RNA extracts were screened for tick-borne encephalitis virus (TBEV) by RT-qPCR targeting the $3^{\prime}$ non-coding region of the TBEV genome with specific primers and probe (Table 2) [36]. Taqman RT-qPCR reactions were performed in a final volume of $20 \mu \mathrm{l}$ using the $\mathrm{iTaq}^{\text {TM }}$ Universal Probes One Step Kit (BioRad Laboratory Inc., Munich, Germany). Each assay contained $10 \mu \mathrm{l}$ Itaq universal probes reaction mix $(2 \times), 2 \mu \mathrm{l}$ of water, $400 \mathrm{nM}$ of forward and reverse primers and $200 \mathrm{nM}$ probe, $0.5 \mu \mathrm{l}$ Iscript advanced reverse transcriptase and $5 \mu \mathrm{l}$ of RNA. Each run included Langat virus RNA as positive control and water as negative control. Thermal cycling conditions of the reaction were as follows: $50^{\circ} \mathrm{C}$ for $10 \mathrm{~min}, 95^{\circ} \mathrm{C}$ for 5 min, 45 cycles at $95^{\circ} \mathrm{C}$ for $15 \mathrm{~s}$, then $60^{\circ} \mathrm{C}$ for $1 \mathrm{~min}$.

\section{Statistical analysis}

The pathogens detected in the nymph pools were expressed as the percentage and minimum infection rate (MIR) calculated as the ratio of the number of positive pools to the total number of analyzed ticks, assuming that only one tick in each pool was positive. MIR was calculated according to site and Borrelia species detected in nymphal pools.

In order to compare the prevalence rates of Borrelia spp. in adult stages of ticks, infectious rates and MIR of different species, a t-test (two sample assuming unequal variances) was conducted using Microsoft Excel (2016) (Microsoft Corp., Redmont, USA). Confidence intervals (95\% CI) were also calculated in Microsoft Excel 2016 for the infection rates and MIR of Borrelia spp. and for the detected Borrelia species in each of the developmental stages. $P$-values $<0.05$ were considered significant.

\section{Results}

In total, 2407 ticks were collected from April to October 2018 in 14 sites from Mecklenburg-Western Pomerania (Fig. 1), all identified as I. ricinus, of nymphal and adult stage only. Nymphs represented the dominant stage collected with 1936 individuals (80.4\%), followed by females $(239 ; 9.9 \%)$ and males $(232 ; 9.6 \%)$ (Table 1). The highest number of ticks was collected from Kieshof, representing $58.4 \%(1406 / 2407)$ of the total ticks, followed by Weitenhagen $(25.9 \%$; 623/2407) and Mannhagen $(6.2 \% ; 149 / 2407)$ (Table 1). In these three locations, collection of ticks was performed monthly.

\section{Borrelia species detected in ticks}

After performing nested PCR and sequencing the amplicons, the prevalence of Borrelia spp. in adult stages was identical: $12.1 \%$ (29/239 of females and 28/232 of males). MIR of $3.3 \%$ was registered in nymphs $(64 / 1936)$ (Table 3).

Sequencing revealed the presence of four Borrelia species in analyzed ticks; three genospecies belonging to the B. burgdorferi (s.l.) group, B. afzelii, B. garinii and B. valaisiana, and one species of the relapsing fever group, $B$. miyamotoi. Out of these identified species, B. afzelii had the highest prevalence in adult ticks 5.5\% (26/471). Borrelia miyamotoi was found in 3.0\% (14/471) of adults, while B. valaisiana was detected in $2.5 \%(12 / 471)$ and $B$. garinii found in $1.1 \%(5 / 471)$ adult ticks (Table 3$)$.

Amongst all four detected Borrelia species in adult ticks, $B$. afzelii had significantly higher infection rates than $B$. garinii $(P=0.0001)$ and $B$. valaisiana $(P=0.02)$ but not significantly different when compared to $B$. miyamotoi $(P=0.06)$. Borrelia miyamotoi showed a statistically significant higher prevalence in adults compared to $B$. garinii $(P=0.04)$ but not significantly different from $B$. valaisiana infection rate $(P=0.69)$. Infection rates of Borrelia valaisiana and $B$. garinii did not show significant differences $(P=0.09)$.

Borrelia afzelii had similar infection rates in both female and male ticks, 5.9\% (14/239) and 5.2\% (12/232), respectively $(P=0.75)$. Nymphs showed a MIR for B. afzelii of 1.8\% (34/1936) (Table 3, Fig. 2). Borrelia miyamotoi was detected in $2.9 \%(7 / 239)$ of $I$. ricinus females and $3.0 \%(7 / 232)$ of males $(P=0.96)$. MIR of B. miyamotoi in nymphs was $0.8 \%(16 / 1936)$ (Table 3 , Fig. 2). Detection of B. valaisiana was confirmed in $3.4 \%(8 / 239)$ tick females and $1.7 \%(4 / 232)$ males, prevalence rates registering similar values (Table 3, Fig. 2) $(P=0.28)$. Pools of $I$. ricinus nymphs were also positive for B. valaisiana, MIR of $0.7 \%$ (13/1936) (Table 3, Fig. 2). All tested I. ricinus females were negative for $B$. garinii, while $2.2 \%$ of male ticks were positive (Table 3 , Fig. 2). Borrelia garinii was found also in one pool of nymphs, MIR of $0.1 \%(1 / 1936)$ (Table 3, Fig. 2).

Considering the infection rates of different Borrelia species in each developmental stage, I. ricinus females had similar prevalence rate of $B$. afzelii when compared to $B$. valaisiana (5.9 vs $3.4 \% ; P=0.20$ ) and $B$. miyamoto $i$ 
Table 3 Borrelia species detected in adult and nymphal I. ricinus stage

\begin{tabular}{|c|c|c|c|c|c|c|c|}
\hline \multirow[t]{2}{*}{ Stage } & \multirow[t]{2}{*}{$N$} & \multirow[t]{2}{*}{$n$} & \multicolumn{5}{|c|}{ No. of PCR positive, \% (95\% Cl) } \\
\hline & & & Borrelia spp. & B. afzelii & B. garinii & B. valaisiana & B. miyamotoi \\
\hline Female & 239 & 239 & $\begin{array}{l}29 / 12.1 \\
(8.0-16.3)\end{array}$ & $\begin{array}{l}14 / 5.9 \\
(2.9-8.9)\end{array}$ & $\begin{array}{l}- \\
-\end{array}$ & $\begin{array}{l}8 / 3.4 \\
(1.1-5.7)\end{array}$ & $\begin{array}{l}7 / 2.9 \\
(0.8-5.1)\end{array}$ \\
\hline Male & 232 & 232 & $\begin{array}{l}28 / 12.1 \\
(7.8-16.3)\end{array}$ & $\begin{array}{l}12 / 5.2 \\
(2.3-8.0)\end{array}$ & $\begin{array}{l}5 / 2.2 \\
(0.3-4.0)\end{array}$ & $\begin{array}{l}4 / 1.7 \\
(0-3.4)\end{array}$ & $\begin{array}{l}7 / 3.0 \\
(0.8-5.2)\end{array}$ \\
\hline Nymph & 1936 & $213^{\mathrm{a}}$ & $\begin{array}{l}64 / 3.3^{b} \\
(2.5-4.1)\end{array}$ & $\begin{array}{l}34 / 1.8^{b} \\
(1.2-2.3)\end{array}$ & $\begin{array}{l}1 / 0.1^{b} \\
(0.0-0.2)\end{array}$ & $\begin{array}{l}13 / 0.7^{b} \\
(0.3-1.0)\end{array}$ & $\begin{array}{l}16 / 0.8^{b} \\
(0.4-1.2)\end{array}$ \\
\hline
\end{tabular}

a Pooled samples

b MIR of pooled samples

Abbreviation: $\mathrm{N}$, number of analyzed samples; $\mathrm{n}$, number of samples/pools; -, no positive samples

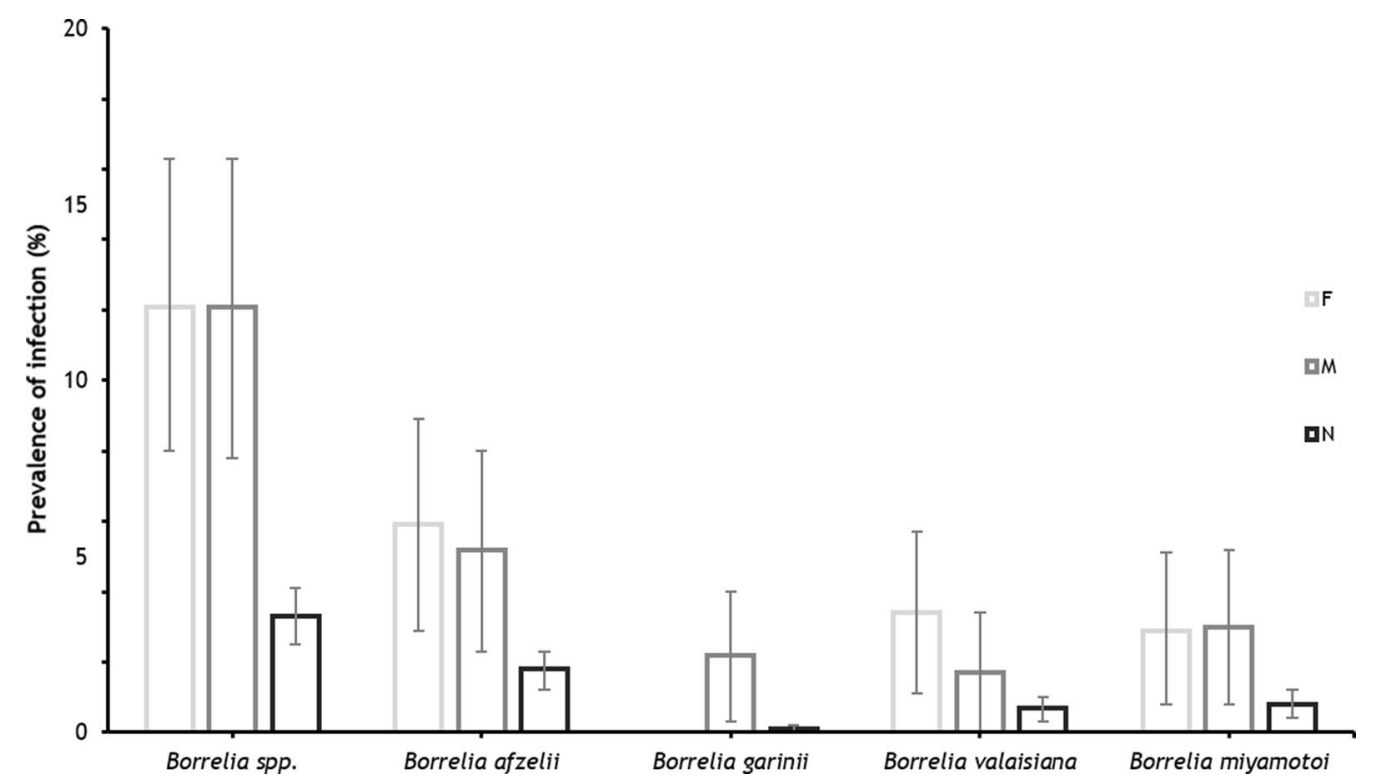

Fig. 2 Borrelia species prevalence in I. ricinus adults and MIR in nymphs. Abbreviations: F, females; M, males; N, nymphs

(5.9 vs $2.9 \% ; P=0.13$ ). In males, prevalence of $B$. afzelii was significantly higher than $B$. valaisiana $(5.2 \mathrm{vs} 1.7 \%$; $P=0.04)$ but at similar rates with $B$. miyamotoi $(5.2$ vs $3.0 \% ; P=0.25)$ and B. garinii (5.2 vs $2.2 \% ; P=0.09)$ (Table 3, Fig. 2).

Borrelia afzelii MIR in nymphs was significantly higher compared to all other three Borrelia species detected (1.8 vs $0.8 \%$ B. miyamotoi, $P=0.01$; vs $0.7 \%$ B. valaisiana, $P=0.002$; vs $0.1 \% B$. garinii, $P<0.0001)$. Borrelia miyamotoi and $B$. valaisiana had similar MIR $(P=0.57)$, and both species registered statistically higher MIR when compared to B. garinii $(P<0.0001$ and $P=0.001$, respectively) (Table 3, Fig. 2).

The highest number of positive ticks for Borrelia spp. was found in Kieshof (13.2\% of adult ticks and MIR of $3.6 \%$ in nymphal pools), followed by Weitenhagen (13.1\% of adult ticks and MIR of $2.6 \%$ in nymphal pools)
(Table 4). The most prevalent species was B. afzelii for both sites: $5.5 \%$ of adult ticks and MIR of $2.0 \%$ for nymphs from Kieshof and $4.9 \%$ adults and MIR of $0.8 \%$ for nymphs from Weitenhagen. Borrelia miyamotoi was the second most prevalent species in both study sites (Kieshof: $4.0 \%$ of adult ticks and MIR of $0.7 \%$ in nymphs; Weitenhagen: $2.5 \%$ adult ticks and MIR of $1.2 \%$ in nymphal pools) (Table 4).

\section{Phylogenetic analysis of Borrelia species from Mecklenburg-Western Pomerania}

Diversity of Borrelia species in north-eastern Germany based on the 16S-23S IGS included four different species. Borrelia afzelii sequences obtained in this study showed high similarity with isolate strains from Norway (GenBank: KY782011), Germany (GenBank: CP002933), Sweden (GenBank: FJ750344) and Ukraine (GenBank: 
Table 4 Positive Borrelia spp. adult ticks and pool of nymphs from the study sites

\begin{tabular}{|c|c|c|c|c|c|c|c|c|c|c|c|c|c|c|c|c|}
\hline \multirow[t]{3}{*}{ Site } & \multirow[t]{3}{*}{ Location } & \multicolumn{15}{|c|}{ No. of positive ticks per developmental stage } \\
\hline & & \multicolumn{3}{|c|}{ Borrelia spp. } & \multicolumn{3}{|c|}{ B. afzelii } & \multicolumn{3}{|c|}{ B. garinii } & \multicolumn{3}{|c|}{ B. valaisiana } & \multicolumn{3}{|c|}{ B. miyamotoi } \\
\hline & & $\mathrm{F}$ & M & N & $\mathrm{F}$ & M & N & $\mathrm{F}$ & M & N & $\mathrm{F}$ & M & N & $\mathrm{F}$ & M & N \\
\hline 1 & Kieshofer & 14 & 22 & 41 & 6 & 9 & 23 & - & 3 & 1 & 3 & 4 & 9 & 5 & 6 & 8 \\
\hline 2 & Ryck & - & - & 1 & - & - & - & - & - & - & - & - & - & - & - & 1 \\
\hline 3 & Weitenhagen & 13 & 3 & 13 & 6 & - & 4 & - & 2 & - & 5 & - & 3 & 2 & 1 & 6 \\
\hline 4 & Loitz & - & 1 & - & - & 1 & - & - & - & - & - & - & - & - & - & - \\
\hline 5 & Carlsruhe & - & - & - & - & - & - & - & - & - & - & - & - & - & - & - \\
\hline 6 & Tempel & - & 1 & - & - & 1 & - & - & - & - & - & - & - & - & - & - \\
\hline 7 & Mannhagen & - & - & 3 & - & - & 3 & - & - & - & - & - & - & - & - & - \\
\hline 8 & Riems & 1 & - & - & 1 & - & - & - & - & - & - & - & - & - & - & - \\
\hline 9 & Ummanz & - & - & 1 & - & - & - & - & - & - & - & - & - & - & - & 1 \\
\hline 10 & Ladebow & - & 1 & 2 & - & 1 & 1 & - & - & - & - & - & 1 & - & - & - \\
\hline 11 & Horst & 1 & - & 1 & 1 & - & 1 & - & - & - & - & - & - & - & - & - \\
\hline 12 & Thiesow & - & - & 2 & - & - & 2 & - & - & - & - & - & - & - & - & - \\
\hline 13 & Wackerow & - & - & - & - & - & - & - & - & - & - & - & - & - & - & - \\
\hline 14 & Annenhof & - & - & - & - & - & - & - & - & - & - & - & - & - & - & - \\
\hline Total & & 29 & 28 & 64 & 14 & 12 & 34 & - & 5 & 1 & 8 & 4 & 13 & 7 & 7 & 16 \\
\hline
\end{tabular}

Abbreviations: $\mathrm{F}$, females; $\mathrm{M}$, males; -, no positive samples

MK790196). Sequences also clustered with strains isolated from Northern and north-eastern Europe (Fig. 3). Four out of six B. garinii isolates from this study were identical with strains isolated from I. ricinus larvae collected from the great tit Parus major in Sweden (GenBank: DQ307377 and DQ307377), while the other two were highly similar also to a strain from the same study in Sweden (GenBank: DQ307376). Borrelia valaisiana sequences obtained in this study, with sizes between 232-312 bp, matched only with the Russian strain Tom4006 (GenBank: CP009117) (Fig. 3). The majority of B. miyamotoi isolates from I. ricinus ticks collected from Mecklenburg-Western Pomerania were identical to isolate Z58 from Austria (GenBank: KP202177) and clustered with strains from Northern Europe and also from eastern European countries (Ukraine and Turkey) (Fig. 3).

\section{Multilocus sequence typing of $B$. miyamotoi}

Seven samples identified as B. miyamotoi by $16 \mathrm{~S}-23 \mathrm{~S}$ IGS nested PCR were selected and analyzed by MLST, targeting eight highly conserved housekeeping genes (nifS, clpA, rplB, pyrG, recG, clpX, pepX and uvrA). Isolates were submitted to the Borrelia spp. MLST database (http://pubmlst.org/borrelia) (sample ID: 2654-2660) (complete batch of sequences is available in Additional file 1). All sequenced samples were $B$. miyamoto $i$ and five of them (sample ID: 2654, 2655, 2656, 2657 and 2659) belonged to the sequence type (ST) 635 . The other two samples (ID: 2658 and 2660) could not be framed in a ST due to poor quality sequences for nifS, but all alleles were distributed to the same ST 635 which corresponds to the EU_T01 isolate identified in 2014, in I. ricinus from Berlin, Germany.

\section{Detection of tick-borne encephalitis virus}

The RT-qPCR performed on I. ricinus RNA did not identified positive samples for TBEV.

\section{Discussion}

The objective of this study was to bring new insights regarding the circulation of Borrelia species and tickborne encephalitis virus (TBEV) in $I$. ricinus ticks collected from vegetation in natural habitats from northeastern Germany. Ixodes ricinus is an exophilic tick species with a wide distribution range in Europe known to feed on a great variety of hosts, records indicating more than 300 different vertebrate host species [37]. Due to these feeding preferences, I. ricinus can circulate various pathogens between host species, causing major health disorders of medical and veterinary importance. The most representative pathogens for which I. ricinus is the main vector in Europe are B. burgdorferi (s.l.), B. miyamotoi, TBEV, agents of the order Rickettsiales (Rickettsia spp. and Anaplasma phagocytophilum) and Babesia protozoans [37]. During our sampling, we managed to collect a relatively high number of $I$. ricinus ticks, nymphs 


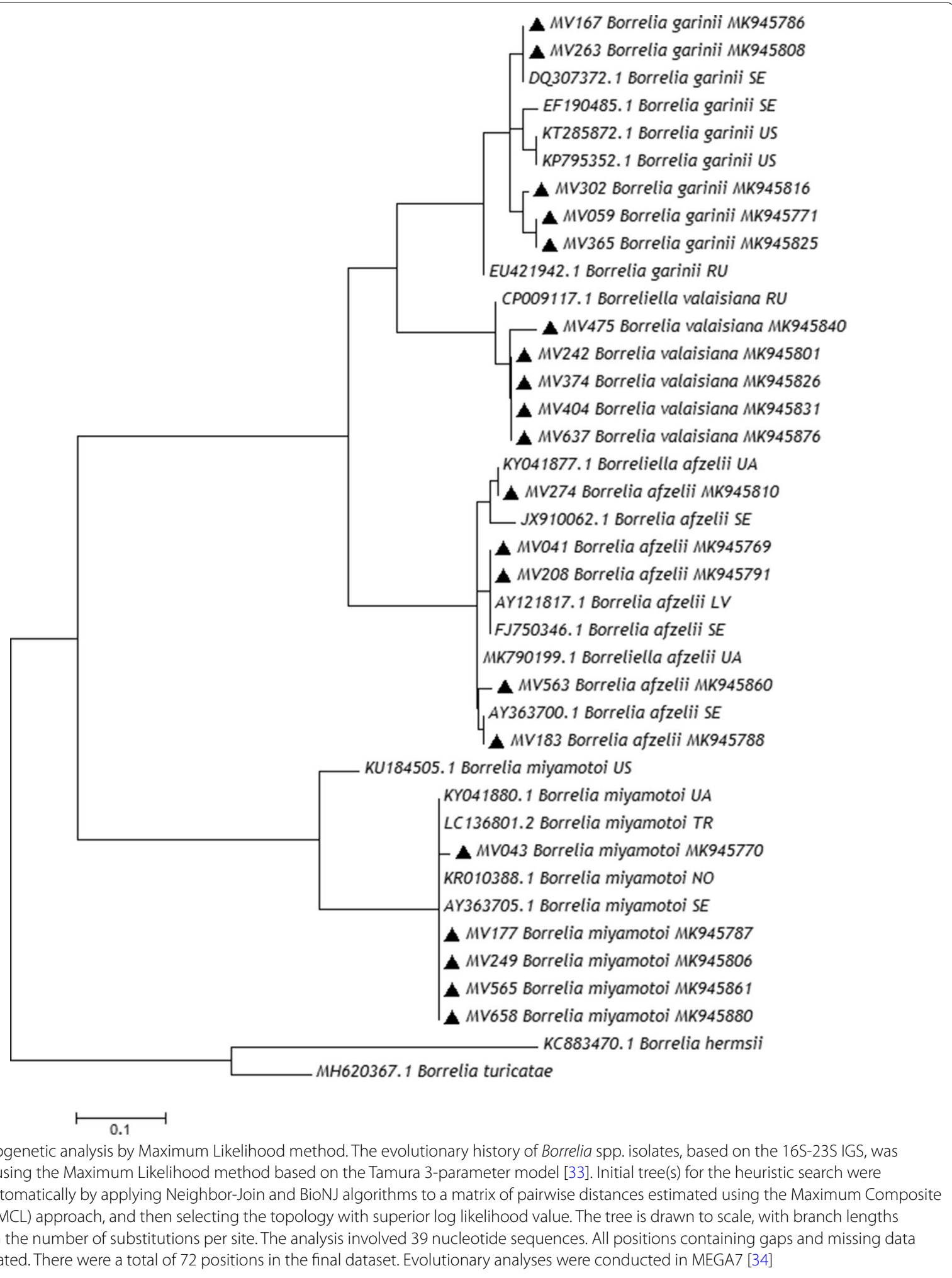


being the most encountered stage in most of the study sites (Table 1). This finding is relevant for public health since nymphs represent the highest threat for humans compared to other tick stages due to their small size that enables them to go unnoticed during feeding corroborated with their marked anthropophily, abundance, and the ability to transmit a broad-range of pathogens [38, 39].

Detection of B. burgdorferi (s.l.) in I. ricinus ticks from Mecklenburg-Western-Pomerania confirms the role of this tick species as the main vector for Lyme disease genospecies. The overall prevalence of $B$. burgdorferi (s.l.) is lower compared to the infection rates registered in other studies from Germany [15, 16, 40-42]. However, a previous study reported similar infection rates in I. ricinus ticks ( $16.8 \%$ of females, $12.9 \%$ of males and $5.7 \%$ of nymphs) collected in 2003 from woodlands in Mecklenburg-Western Pomerania [43], potentially indicating a constant circulation of B. burgdorferi (s.l.) in the tick population from this region. Also, the minimum infection rate of nymphs reported in our study might actually be substituted by a higher infection rate, each pool potentially containing more than one positive nymph for Borrelia spp. As for the comparison between developmental stages, adult ticks had higher prevalence rates. This, in fact, can be explained by the life-cycle of hard ticks, with the adult stage having a greater chance to acquire the pathogens after feeding twice on two separate hosts, while for reaching nymphal stage only one feeding is necessary during the larval stage.

Sequencing revealed three genospecies of the $B$. burgdorferi (s.l.) complex, B. afzelii having the highest prevalence, followed by B. valaisiana and B. garinii. These results are in concordance with current knowledge indicating $B$. afzelii as the most common genospecies in Europe. In the event of clinical manifestations following B. afzelii infection, symptoms are represented by acrodermatitis chronica atrophicans and chronic skin disease [44]. Rodents are the reservoir hosts for B. afzelii in Europe (e.g. mice and voles) [45], representing important feeding hosts for immature stages of I. ricinus. Detection of B. burgdorferi (s.l.) in rodent populations from Germany with infection rates up to $49.1 \%$ confirmed the role of these small mammals as reservoir hosts [40, 42]. The collection sites for ticks in the current study are extensive forest areas that could contain high abundance of voles or other rodents acting as infected reservoir hosts for the local tick population.

Borrelia valaisiana was the second most prevalent genospecies in questing ticks from the studied area. Primary reservoir hosts for B. valaisiana and Borrelia garinii are ground-feeding birds (e.g. the common blackbird, Turdus merula, and the song thrush, Turdus philomelos) which feed in the habitats of ticks and become infested with these arthropods at higher rates [46]. In each year, over five million migratory birds and 27 species of water birds use habitats from Ruegen Island and the coast of Mecklenburg-West Pomerania as stopover sites in their migration between northern European countries and Central Europe and Africa [47]. This could mean that birds can also contribute to the long-distance distribution of tick-borne pathogens due to their role as reservoir hosts for infectious agents and also as hosts for immature stages of ticks.

Relapsing fever agent Borrelia miyamotoi was detected in $1.2 \%$ of the analysed ticks, this data being the first reported for Mecklenburg-Western Pomerania. In addition, the first available data regarding infection rates of B. miyamotoi in ticks from Northern Germany became available in 2018 , when $2.1 \%$ of $I$. ricinus ticks collected from the city of Hanover were positive [16]. The prevalence of the current study is therefore in concordance with B. miyamotoi infectious rates found in I. ricinus ticks from Europe, ranging from $0.4 \%$ in Estonia to 3.5\% in France and Germany [21, 48, 49]. The fact that this pathogen is present in Mecklenburg-Western Pomerania can have significance for clinicians since $B$. miyamotoi can cause febrile illness characterised by fever, nausea, fatigue, headache, chills, myalgia, arthralgia and meningoencephalitis [21].

The phylogenetic tree based on 16S-23S IGS shows that strains of Borrelia spp. found in the present study are closely related with isolates from Northern and northeastern Europe (Fig. 3). This might indicate a circulation of these strains within this north-eastern region, most likely birds being involved in the dissemination in different regions of Northern Europe of the infected ticks and perhaps the Borrelia genospecies for which birds serve as reservoir hosts.

Multilocus sequence typing of eight housekeeping genes (nifS, clpA, rplB, pyrG, recG, clpX, pepX and $u v r A$ ) of $B$. miyamotoi isolates matched to ST 635 corresponding to the EU_T01 isolate identified in $I$. ricinus ticks from Berlin (https://pubml st.org/bigsdb?page $=$ info\&db=pubmlst_borrelia_isola tes\&id $=1279$ ) which can indicate a low polymorphism between $B$. miyamotoi strains from the northern part of Germany. Performing MLST at a larger scale, by including an extensive number of isolates, will be useful to follow the subtle modifications between the strains and to study the phylogenetic relationships between $B$. miyamotoi strains isolated from Germany and Europe, this method having a high power of discrimination between strains [50].

Detection of TBEV in the tick samples analyzed in the present study was unsuccessful. In Germany, high 
endemic regions for TBEV are located in the southern part of the country (e.g. Bavaria and Baden-Wuerttemberg) but sporadic cases were also reported from the upper north regions of the country, recently including Mecklenburg-Western Pomerania [26]. Signs of TBEV circulation in this area were also shown in 2007 by detection of TBEV RNA in I. ricinus ticks [28] and identification of anti-TBEV antibodies in small ruminants [30], and wildlife [29]. Even though we did not detect TBEV RNA in the collected ticks, several factors could contribute to a future expansion of the virus foci in Mecklenburg-Western Pomerania. Climate change is one of the factors that was shown to influence the tick population in Northern Europe, increasing the duration of the vegetation period throughout the year and the humidity levels as well [51]. Also, changes in land use and movement of animal hosts could influence the abundance of tick populations in the region. Mecklenburg-Western Pomerania represents a popular destination for tourists that have many outdoor activities, raising the risk of exposure to tick bites in the area. Performing larger scale studies might contribute to an accurate estimation of TBEV infection rates in tick populations from Mecklenburg-Western Pomerania.

\section{Conclusions}

The present study is adding new information regarding the distribution of B. miyamotoi in tick populations from Northern Germany which should be considered by medical clinicians when treating patients after a tick bite. The infection rate of $B$. miyamotoi in ticks was similar to other reports in tick populations from Europe suggesting that this relapsing fever agent might be well established in the local tick population and small mammal reservoir hosts. In addition, the detection of $B$. afzelii, $B$. garinii and B. valaisiana corroborating previous studies, suggests a constant circulation of B. burgdorferi (s.l.) in the tick population from this region. While in this study detection of tick-borne encephalitis virus was not possible, other reports showed signs of virus circulation in the area and extensive future studies should determine the natural foci of TBEV in Mecklenburg-Western Pomerania in order to reassess the risks for public health.

\section{Supplementary information}

Supplementary information accompanies this paper at https://doi. org/10.1186/s13071-020-3969-7.

Additional file 1. Complete batch of Borrelia miyamotoi sequences corresponding to the following genes: $C I p A, c l p X$, nifS, pepX, recG, pyrG, rp/B, uvrA.

\section{Abbreviations}

MIR: Minimum infection rate; RT-qPCR: Reverse transcription quantitative polymerase chain reaction; BLAST: Basic local alignment search tool; IGS:
Intergenic spacer; ST: Sequence type; Cl: Confidence interval; MLST: Multilocus sequence typing.

\section{Acknowledgements}

We thank Dr Gabriele Margos for valuable input in the MLST analysis of Borrelia miyamotoi. Kersten Biebl (Institute of Diagnostic Virology, Friedrich-LoefflerInstitute) for performing the sequencing and Dr Kerstin Wernike (Institute of Diagnostic Virology, Friedrich-Loeffler-Institute) for kindly providing positive control for tick-borne encephalitis RT-qPCR reaction.

\section{Authors' contributions}

CS and CR organized and designed the study. CR, CS, OT, AV and EW organized and performed the field work. CR and OT performed the analysis of ticks in the laboratory. CR and CS analyzed the data and drafted the manuscript. CS critically reviewed the manuscript. All authors read and approved the final manuscript.

\section{Funding}

Not applicable.

\section{Availability of data and materials}

Consensus Borrelia 16S-23S IGS sequences were deposited in the GenBank database under the Accession numbers MK945767-MK945887.

Ethics approval and consent to participate

Not applicable.

\section{Consent for publication}

Not applicable.

\section{Competing interests}

The authors declare that they have no competing interests.

\section{Author details}

${ }^{1}$ Institute of Infectology, Friedrich-Loeffler-Institut, Südufer 10, 17943 Greifswald-Insel Riems, Germany. ${ }^{2}$ Institute of Molecular Virology and Cell Biology, Friedrich-Loeffler-Institut, Greifswald-Insel Riems, Germany. ${ }^{3}$ Department of Biology, University of Greifswald, Domstrasse 11, 17489 Greifswald, Germany.

Received: 11 November 2019 Accepted: 13 February 2020

Published online: 27 February 2020

\section{References}

1. Sonenshine DE. Biology of ticks. Oxford: Oxford University Press; 1991.

2. Egyed L, Elo P, Sreter-Lancz Z, Szell Z, Balogh Z, Sreter T. Seasonal activity and tick-borne pathogen infection rates of Ixodes ricinus ticks in Hungary. Ticks Tick Borne Dis. 2012;3:90-4.

3. Rubel F, Brugger K, Monazahian M, Habedank B, Dautel H, Leverenz S, et al. The first German map of georeferenced ixodid tick locations. Parasites Vectors. 2014;7:477.

4. Rizzoli A, Hauffe H, Carpi G, Vourc HG, Neteler M, Rosa R. Lyme borreliosis in Europe. Eurosurveillance. 2011;16:27.

5. Mansfield KL, Johnson N, Phipps LP, Stephenson JR, Fooks AR, Solomon T. Tick-borne encephalitis virus-a review of an emerging zoonosis. J Gen Virol. 2009;90:1781-94.

6. Medlock JM, Hansford KM, Bormane A, Derdakova M, Estrada-Pena A, George JC, et al. Driving forces for changes in geographical distribution of Ixodes ricinus ticks in Europe. Parasites Vectors. 2013;6:1.

7. Rosa PA, Tilly K, Stewart PE. The burgeoning molecular genetics of the Lyme disease spirochaete. Nat Rev Microbiol. 2005;3:129-43.

8. Enkelmann J, Bohmer M, Fingerle V, Siffczyk C, Werber D, Littmann M, et al. Incidence of notified Lyme borreliosis in Germany, 2013-2017. Sci Rep. 2018;8:14976.

9. Waindok P, Schicht S, Fingerle V, Strube C. Lyme borreliae prevalence and genospecies distribution in ticks removed from humans. Ticks Tick Borne Dis. 2017;8:709-14.

10. Stanek G, Wormser GP, Gray J, Strle F. Lyme borreliosis. Lancet. 2012;379:461-73. 
11. Venczel R, Knoke L, Pavlovic M, Dzaferovic E, Vaculova T, Silaghi C, et al. A novel duplex real-time PCR permits simultaneous detection and differentiation of Borrelia miyamotoi and Borrelia burgdorferi sensu lato. Infection. 2016:44:47-55.

12. Tappe J, Jordan D, Janecek E, Fingerle V, Strube C. Revisited: Borrelia burgdorferi sensu lato infections in hard ticks (Ixodes ricinus) in the city of Hanover (Germany). Parasites Vectors. 2014;7:441.

13. May K, Jordan D, Fingerle V, Strube C. Borrelia burgdorferi sensu lato and co-infections with Anaplasma phagocytophilum and Rickettsia spp. in Ixodes ricinus in Hamburg, Germany. Med Vet Entomol. 2015;29:425-9.

14. Franke J, Hildebrandt A, Meier F, Straube E, Dorn W. Prevalence of Lyme disease agents and several emerging pathogens in questing ticks from the German Baltic coast. J Med Entomol. 2011;48:441-4.

15. Fingerle V, Munderloh UG, Liegl G, Wilske B. Coexistence of ehrlichiae of the phagocytophila group with Borrelia burgdorferi in Ixodes ricinus from southern Germany. Med Microbiol Immunol. 1999;188:145-9.

16. Blazejak K, Raulf MK, Janecek E, Jordan D, Fingerle V, Strube C. Shifts in Borrelia burgdorferi (s.l.) geno-species infections in /xodes ricinus over a 10-year surveillance period in the city of Hanover (Germany) and Borrelia miyamotoi-specific Reverse Line Blot detection. Parasites Vectors. 2018:11:304.

17. Eshoo MW, Crowder CD, Carolan HE, Rounds MA, Ecker DJ, Haag H, et al. Broad-range survey of tick-borne pathogens in southern Germany reveals a high prevalence of Babesia microti and a diversity of other tickborne pathogens. Vector Borne Zoonotic Dis. 2014;14:584-91.

18. Bingsohn L, Beckert A, Zehner R, Kuch U, Oehme R, Kraiczy P, et al. Prevalences of tick-borne encephalitis virus and Borrelia burgdorferi sensu lato in Ixodes ricinus populations of the Rhine-Main region, Germany. Ticks Tick Borne Dis. 2013;4:207-13.

19. Schicht S, Junge S, Schnieder T, Strube C. Prevalence of Anaplasma phagocytophilum and coinfection with Borrelia burgdorferi sensu lato in the hard tick Ixodes ricinus in the city of Hanover (Germany). Vector Borne Zoonotic Dis. 2011;11:1595-7.

20. Sinski E, Welc-Faleciak R, Zajkowska J. Borrelia miyamotoi: a human tickborne relapsing fever spirochete in Europe and its potential impact on public health. Adv Med Sci. 2016;61:255-60.

21. Krause PJ, Fish D, Narasimhan S, Barbour AG. Borrelia miyamotoi infection in nature and in humans. Clin Microbiol Infect. 2015;21:631-9.

22. Michelitsch A, Wernike K, Klaus C, Dobler G, Beer M. Exploring the reservoir hosts of tick-borne encephalitis virus. Viruses. 2019;11:E669.

23. European Centre for Disease Prevention and Control. Epidemiological situation of tick-borne encephalitis in the European Union and European Free Trade Association countries. Stockholm: ECDC; 2012

24. Donoso Mantke O, Escadafal C, Niedrig M, Pfeffer M, Working group for tick-borne encephalitis virus C. Tick-borne encephalitis in Europe, 2007 to 2009. Euro Surveill. 2011. https://doi.org/10.2807/ese.16.39.19976-en.

25. Katargina O, Russakova S, Geller J, Kondrusik M, Zajkowska J, Zygutiene $M$, et al. Detection and characterization of tick-borne encephalitis virus in Baltic countries and eastern Poland. PLoS ONE. 2013;8:e61374.

26. Hellenbrand W, Kreusch T, Bohmer MM, Wagner-Wiening C, Dobler G, Wichmann O, et al. Epidemiology of tick-borne encephalitis (TBE) in Germany, 2001-2018. Pathogens. 2019:8:42

27. Hemmer CJ, Littmann M, Lobermann M, Lafrenz M, Bottcher T, Reisinger EC. Tickborne meningoencephalitis, first case after 19 years in northeastern Germany. Emerg Infect Dis. 2005;11:633-4.

28. Frimmel S, Krienke A, Riebold D, Loebermann M, Littmann M, Fiedler K, et al. Tick-borne encephalitis virus habitats in North East Germany: reemergence of TBEV in ticks after 15 years of inactivity. Biomed Res Int. 2014;2014:308371.

29. Frimmel S, Leister M, Lobermann M, Feldhusen F, Seelmann M, Suss J, et al. Seroprevalence of tick-borne-encephalitis virus in wild game in Mecklenburg-Western Pomerania (north-eastern Germany). Ticks Tick Borne Dis. 2016;7:1151-4.

30. Frimmel S, Lobermann M, Feldhusen F, Seelmann M, Stiasny K, Suss J, et al. Detection of tick-borne encephalitis virus antibodies in sera of sheep and goats in Mecklenburg-Western Pomerania (north-eastern Germany). Ticks Tick Borne Dis. 2019;10:901-4.

31. Estrada-Peña A, Bouattour A, Camicas J-L, Walker A. Ticks of domestic animals in the mediterranean region: a guide to identification of species. Zaragoza: University of Zaragoza; 2004.

32. Bunikis J, Garpmo U, Tsao J, Berglund J, Fish D, Barbour AG. Sequence typing reveals extensive strain diversity of the Lyme borreliosis agents
Borrelia burgdorferi in North America and Borrelia afzelii in Europe. Microbiology. 2004;150:1741-55.

33. Tamura K. Estimation of the number of nucleotide substitutions when there are strong transition-transversion and $\mathrm{G}+\mathrm{C}$-content biases. Mol Biol Evol. 1992;9:678-87.

34. Kumar S, Stecher G, Tamura K. MEGA7: molecular evolutionary genetics analysis version 7.0 for bigger datasets. Mol Biol Evol. 2016;33:1870-4.

35. Margos G, Binder K, Dzaferovic E, Hizo-Teufel C, Sing A, Wildner M, et al. PubMLST.org - the new home for the Borrelia MLSA database. Ticks Tick Borne Dis. 2015;6:869-71.

36. Schwaiger M, Cassinotti P. Development of a quantitative real-time RTPCR assay with internal control for the laboratory detection of tick borne encephalitis virus (TBEV) RNA. J Clin Virol. 2003;27:136-45.

37. Rizzoli A, Silaghi C, Obiegala A, Rudolf I, Hubalek Z, Foldvari G, et al. Ixodes ricinus and its transmitted pathogens in urban and peri-urban areas in Europe: new hazards and relevance for public health. Front Public Health. 2014;2:251

38. Vassalo M, Paul RE, Perez-Eid C. Temporal distribution of the annual nymphal stock of Ixodes ricinus ticks. Exp Appl Acarol. 2000;24:941-9.

39. Vassallo M, Perez-Eid C. Comparative behavior of different life-cycle stages of Ixodes ricinus (Acari: Ixodidae) to human-produced stimuli. J Med Entomol. 2002:39:234-6.

40. Obiegala A, Krol N, Oltersdorf C, Nader J, Pfeffer M. The enzootic life-cycle of Borrelia burgdorferi (sensu lato) and tick-borne rickettsiae: an epidemiological study on wild-living small mammals and their ticks from Saxony, Germany. Parasites Vectors. 2017;10:115.

41. Szekeres S, Lugner J, Fingerle V, Margos G, Foldvari G. Prevalence of Borrelia miyamotoi and Borrelia burgdorferi sensu lato in questing ticks from a recreational coniferous forest of East Saxony, Germany. Ticks Tick Borne Dis. 2017;8:922-7

42. Galfsky D, Krol N, Pfeffer M, Obiegala A. Long-term trends of tick-borne pathogens in regard to small mammal and tick populations from Saxony, Germany. Parasites Vectors. 2019;12:131.

43. Brunnemann CE. Prevalence of Borrelia burgdorferi sensu lato in Ixodes ricinus ticks in eastern West Pomerania. Greifswald: Medizinischen Fakultät der Ernst-Moritz-Arndt-Universität Greifswald; 2010.

44. Strnad M, Honig V, Ruzek D, Grubhoffer L, Rego ROM. Europe-wide metaanalysis of Borrelia burgdorferi sensu lato prevalence in questing Ixodes ricinus ticks. Appl Environ Microbiol. 2017;83:15.

45. Kurtenbach K, De Michelis S, Etti S, Schafer SM, Sewell HS, Brade V, et al. Host association of Borrelia burgdorferi sensu lato-the key role of host complement. Trends Microbiol. 2002:10(2):74-9.

46. Klaus C, Gethmann J, Hoffmann B, Ziegler U, Heller M, Beer M. Tick infestation in birds and prevalence of pathogens in ticks collected from different places in Germany. Parasitol Res. 2016;115:2729-40.

47. Heinicke TUK. Vogelzug in Ostdeutschland I/1, wasservögel, entenvögel, lappen und seetaucher, kormoran, löffler und reiher. Beringungszentrale Hiddensee, Landesamt für Umwelt, Naturschutz und Geologie Mecklenburg-Vorpommern. Berichte der Vogelwarte Hiddensee 18; 2007

48. Richter D, Schlee DB, Matuschka FR. Relapsing fever-like spirochetes infecting European vector tick of Lyme disease agent. Emerg Infect Dis. 2003;9:697-701.

49. Geller J, Nazarova L, Katargina O, Jarvekulg L, Fomenko N, Golovljova I. Detection and genetic characterization of relapsing fever spirochete Borrelia miyamotoi in Estonian ticks. PLoS ONE. 2012;7:e51914.

50. Margos G, Vollmer SA, Ogden NH, Fish D. Population genetics, taxonomy, phylogeny and evolution of Borrelia burgdorferi sensu lato. Infect Genet Evol. 2011;11:1545-63.

51. Gray JS, Dautel H, Estrada-Pena A, Kahl O, Lindgren E. Effects of climate change on ticks and tick-borne diseases in europe. Interdiscip Perspect Infect Dis. 2009;2009:593232.

\section{Publisher's Note}

Springer Nature remains neutral with regard to jurisdictional claims in published maps and institutional affiliations. 